\title{
The Influence of the Formulation Components and the Mixing Technology on Physical and Mechanical Properties of Abrasive Wheel
}

\author{
Andrey Romanenko ${ }^{1}$, Dmitry Shatko ${ }^{1, *}$ and Pavel Strelnikov ${ }^{1}$ \\ ${ }^{1}$ T.F. Gorbachev Kuzbass State Technical University, 28 Vesennyaya, Kemerovo, 650000, Russia
}

\begin{abstract}
The influence of the components of the abrasive tool formulation and the technology of mixing the components on physical and mechanical properties is discussed in the article. The technology for the manufacture of a ceramic-bond abrasive tool is presented. The main factors that determine the properties of an abrasive tool are described. The data used in the calculation of the formulation are analyzed, such as: type of abrasive material, grain size, hardness, type of bond, structure, filler. The importance of the process of mixing components of grinding tools at the stage of their manufacture is substantiated.The generalized statistical models of the dependence of physical and mechanical properties on the components of the formulation are presented. The model describing the abrasive mixing process is developed. Based on the results obtained, conclusions are formulated in the form of practical recommendations for improving the properties of the abrasive wheel based on the selection of the components of the formulation and the technology of their mixing.
\end{abstract}

\section{Introduction}

In the process of grinding, it is necessary to ensure the specified grinding speed, the specified roughness, the shape of the part within tolerance, the absence of burns on the cut surface of the part. These requirements define the abrasive tool quality indicators and its manufacturing technology [1-3].

Ceramic-bond wheels are the most common in finish grinding. The technology of the manufacture of ceramic-bond abrasive tools consists of the following main steps:

1. Preparation of the molding compound.

The process is carried out in the following sequence:

- the abrasive material mixing;

- the introduction of ceramic bond;

- the introduction of filler, if necessary.

2. Wheel compression molding.

3. Drying and firing molded wheels.

The process of abrasive mixing is the most important step, having the greatest impact on the abrasive tool quality.

\footnotetext{
*Corresponding author: shdb.tm@kuzstu.ru
} 
The main factors determining the abrasive tool properties and, accordingly, its composition, are the desired finish, the material of the workpiece, as well as the cost of grinding.

The formulation for the manufacture of an abrasive tool is determined depending on the operating conditions of the tool, the type of material being cut, the grinding process performance, as well as the tool manufacturing cost.

When calculating the formulation, it is necessary to determine the following data:

1. The type of abrasive material and its specific weight. When choosing an abrasive material, it is necessary to try to increase the strength of abrasive grains (especially fatigue strength) and their wear resistance.

2. Grit number. This parameter depends on the requirements for to the cut surface roughness.

3. Hardness. When choosing the wheel hardness, it is necessary to take into account changes in the cutting force per abrasive grain - with increasing force, it is recommended to select harder wheels and, conversely, reducing force requires a decrease in hardness.

4. The type of ceramic bond. The bond type is determined by its tensile strength.

5. Structure. Cutting speed increasing requires the use of more open structures of grinding wheels, especially if grinding is done by chips of large cross sections.

6 . Filler. There are two types of fillers:

- burnable fillers, which are usually crushed fruit pits up to $1.2 \mathrm{~mm}$ in size, during burn-up of which pores in the body of the abrasive tool form;

- non-burnable fillers are fused alumina or hollow glass microspheres up to $120 \mu \mathrm{m}$ in size, which, when destroyed in the process of a wheel operation, create additional cutting edges.

The type of filler and its percentage are determined by physical and mechanical properties of the abrasive tool required by its structure.

The physical and mechanical properties of the workpiece and its reliability in further use largely depend on grinding conditions; the internal structure of the abrasive tool and its manufacturing technology being a significant factor [4-7].

The grinding wheel is a composite body consisting of grains, bond and fillers. It should be noted that each of these components has its own physical and mechanical properties (density, size and hardness of the original particles, modulus of viscosity); all this determines the uneven distribution of the components of the formulation in the mixed abrasive volume and contributes to the appearance of conglomerates of particles from the mixed components. This phenomenon can lead to an imbalance in the manufactured tool and significantly degrade grinding quality. Consequently, this factor must be considered when choosing the components of the grinding wheel formulation and their mixing technology.

As indicated above, the choice of the components of the formulation is determined by the necessary properties of the tool to be manufactured [8-11], and the main factor determining the internal structure of the wheel and the distribution of the components of the formulation in the wheel body is the mixing process.

In addition, the performance of the grinding wheel is greatly influenced by the shape of abrasive grain in its structure [12-15].

\section{Theoretical and experimental research}

The purpose of the present work is to develop a model that allows describing the process of abrasive preparation. This model should provide an assessment of the effect of the components of the formulation, as well as the mixing technology on physical and mechanical properties of the abrasive wheel. 
Taking into account the fact that, at present, the manufacturers of abrasive tools mainly use rotary drum mixers with an agitator when mixing abrasive, it was decided to model this particular process.

The main criterion for selecting a model was the possibility to evaluate the process in terms of various process parameters, while the model itself remained unchanged.

On the basis of the analysis performed, it can be concluded that a model built on the basis of the theory of Markov chains optimally fits the conditions of the problem being solved.

The proposed model is based on the cellular principle in describing the nature of the movement of the mixed components of abrasive. An important advantage of the model is the possibility of taking into account the probabilistic nature of the mixing process.

At abrasive manufacturing plants, rotary drum mixers with an agitator located eccentrically to rotating housing are most widely used for the abrasive preparation. A typical model of such an installation is shown schematically in Figure 1.

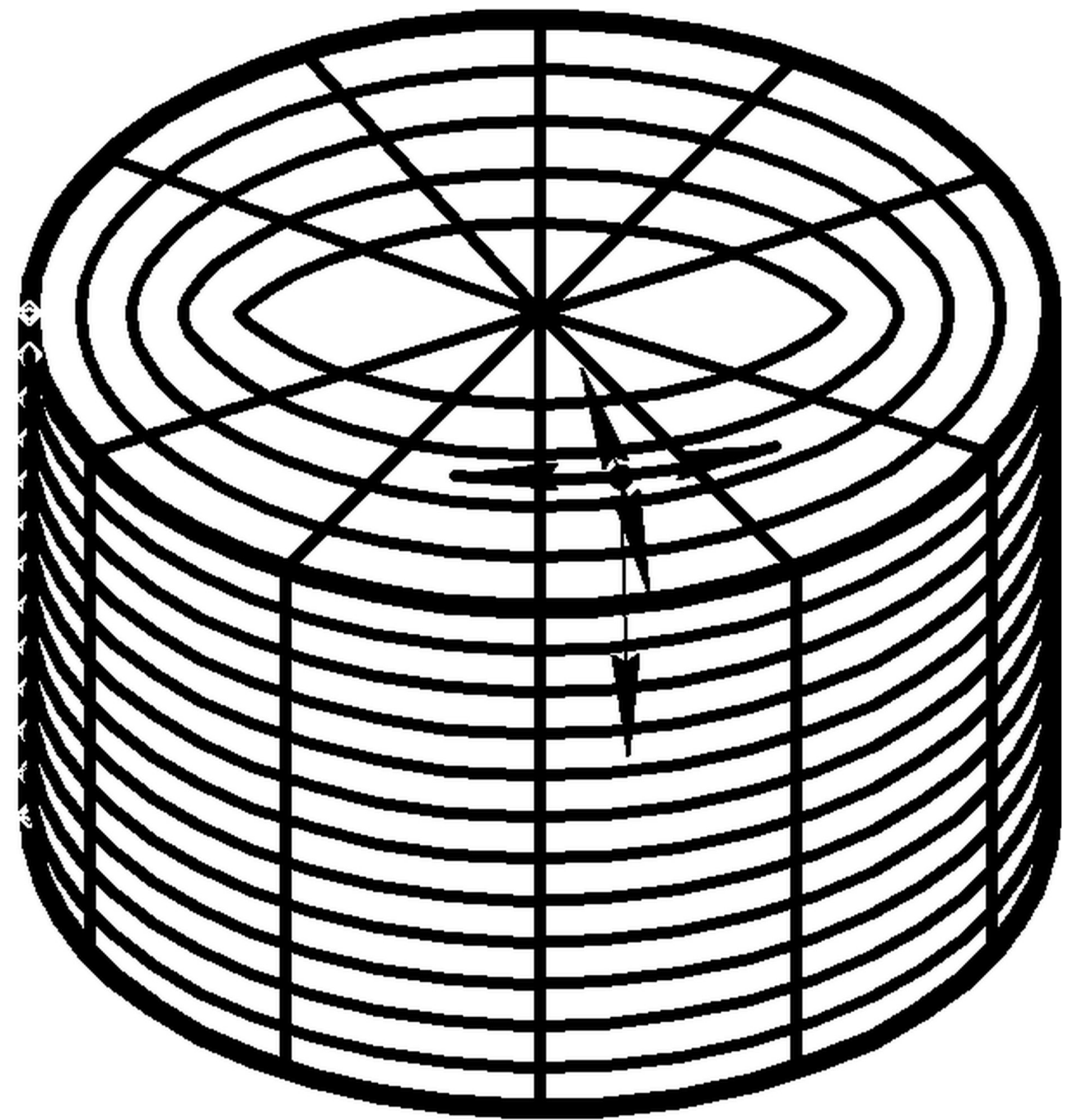

Fig. 1. Cell model of mixed mass in a drum mixer. 
When simulating the mixing process, the following parameters were taken into account; the mixed mass modulus of viscosity, physical and mechanical properties of the mixed components, the mixer rotational rate. The simulation results are shown in Fig. 2, where the following notations are agreed:

$-\omega_{1}, \omega_{0}-$ rotation frequency of the agitator and the drum housing;

$-\sigma-$ root-mean-square deviation of the abrasive concentration in the mass;

$-\eta$ - modulus of viscosity:

- $\mathrm{k}$ - state transition number;

- $\rho_{1}$ and $\rho_{\mathrm{cp}}-$ specific weight of abrasive and average specific weight of the mass.

Figure 2, a) shows the dependence of the root-mean-square deviation of abrasive grains, stability of their concentration in the mass being achieved, on the difference between their specific weight and the average mixture density.

Figure 2, b) demonstrates the dependence of the required number of state transitions of the mixed mass to achieve stability of the concentration of abrasive grains depending on the modulus of viscosity.

Figures 2, c) and d) present the change in the root-mean-square deviation of the concentration of abrasive grains in the mixed mass cells during the mixing process with its various properties and the speed of movement of the working bodies.

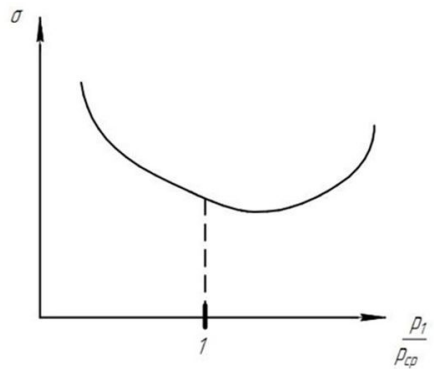

a)

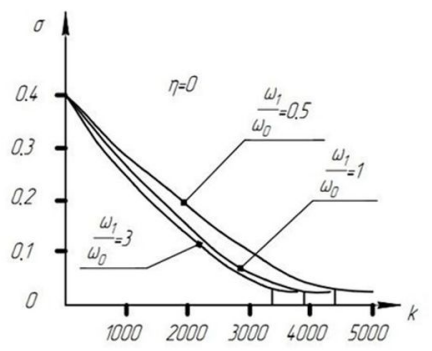

c)

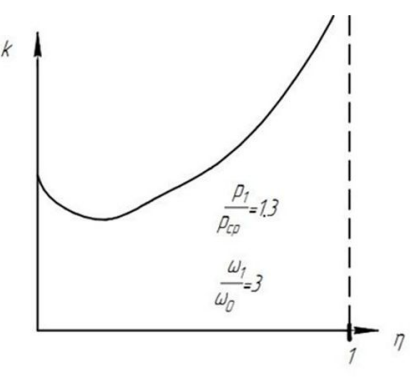

b)

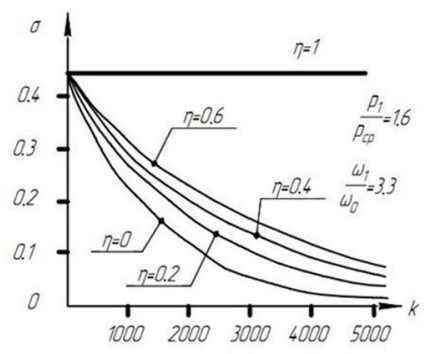

d)

Fig. 2. Simulation of the mixing process in a drum mixer.

Based on the analysis of the graphs, the following conclusions can be drawn:

- the main factor affecting the mixing time to achieve the desired uniformity is the modulus of abrasive viscosity;

- the main factor affecting the uniform distribution of the components of the mixture formulation in the mixed volume is the difference between the specific densities of the components.

Thus, to improve the quality of the mixed mass, it is necessary to minimize the modulus of the mixed mass viscosity, to reduce the difference between specific gravities of the mixed components and the optimal order of introduction of the mixed components.

The main indicators that determine physical and mechanical properties of the wheel are hardness and strength of the wheel. Based on these indicators to assess the effect of the 
components of the formulation on physical and mechanical properties, we select the following indicators:

- tensile strength of the abrasive wheel;

- compressive strength of the abrasive wheel;

- cross breaking strength of the abrasive wheel;

- impact strength.

After processing the obtained experimental data, generalized statistical models were obtained, evaluating the degree of influence of individual components of the formulation on tensile, compressive, cross breaking and impact strength.

In addition to assessing the influence of individual components on physical and mechanical properties, their stability was evaluated. As an evaluation criterion, the root-mean-square deviation of the test results depending on the components of the formulation was selected; and the corresponding models were constructed.

\section{Results and discussion}

The dependences obtained have the form of first-order polynomials. The parameters of statistical models are presented in tables 1-4.

Table 1. Parameters of static models of tensile strength and its root-mean-square deviation.

\begin{tabular}{|c|c|c|c|c|}
\hline \multirow{2}{*}{ Model members } & \multicolumn{2}{|c|}{ Pair correlation coefficients } & \multicolumn{2}{c|}{ Static model coefficients } \\
\cline { 2 - 5 } & & & & \\
\hline $\mathrm{a}_{\mathrm{o}}$ & - & - & 821.632 & -34.281 \\
\hline $\mathrm{V}_{\text {grains }}$ & 0.170 & 0.215 & -0.286 & -1.257 \\
\hline $\mathrm{V}_{\text {fused aluminia }}$ & 0.251 & -0.362 & 9.090 & -0.948 \\
\hline $\mathrm{V}_{\text {glass }}$ & 0.580 & -0.215 & 37.393 & -2.594 \\
\hline $\mathrm{V}_{\text {pits }}$ & -0.471 & 0.677 & -40.884 & 7.943 \\
\hline $\mathrm{V}_{\text {bonds }}$ & 0.403 & 0.474 & 4.363 & 4.772 \\
\hline
\end{tabular}

Table 2. Parameters of static models of compressive strength and its root-mean-square deviation.

\begin{tabular}{|c|c|c|c|c|}
\hline \multirow{2}{*}{ Model members } & \multicolumn{2}{|c|}{ Pair correlation coefficients } & \multicolumn{2}{c|}{ Static model coefficients } \\
\cline { 2 - 5 } & & & & \\
\hline $\mathrm{a}_{\mathrm{o}}$ & - & - & 46.886 & 0.98655 \\
\hline $\mathrm{V}_{\text {grains }}$ & -0.293 & 0.331 & -0.16287 & -0.093 \\
\hline $\mathrm{V}_{\text {fused aluminia }}$ & 0.588 & -0.449 & 0.103 & -0.094 \\
\hline $\mathrm{V}_{\text {glass }}$ & 0.518 & -0.469 & 0.11491 & -0.199 \\
\hline $\mathrm{V}_{\text {pits }}$ & -0.622 & 0.435 & -0.033 & 0.194 \\
\hline $\mathrm{V}_{\text {bonds }}$ & 0.605 & -0.411 & 0.280 & 0.331 \\
\hline
\end{tabular}

Table 3. Parameters of static models of cross breaking strength.

\begin{tabular}{|c|c|c|}
\hline Model members & Pair correlation coefficients & Static model coefficients \\
\hline $\mathrm{a}_{\mathrm{o}}$ & - & 1400.4873 \\
\hline $\mathrm{V}_{\text {grains }}$ & -0.080 & -0.05928 \\
\hline $\mathrm{V}_{\text {fused aluminia }}$ & 0.432 & 0.03475 \\
\hline $\mathrm{V}_{\text {glass }}$ & 0.592 & 0.07273 \\
\hline $\mathrm{V}_{\text {pits }}$ & -0.646 & -0.04357 \\
\hline $\mathrm{V}_{\text {bonds }}$ & 0.217 & 0.32100 \\
\hline
\end{tabular}

Table 4. Parameters of static model of impact strength. 


\begin{tabular}{|c|c|c|}
\hline Model members & Pair correlation coefficients & Static model coefficients \\
\hline $\mathrm{a}_{\mathrm{o}}$ & - & 30.077 \\
\hline $\mathrm{V}_{\text {grains }}$ & -0.473 & -0.3276 \\
\hline $\mathrm{V}_{\text {fused aluminia }}$ & 0.590 & 0.04577 \\
\hline $\mathrm{V}_{\text {glass }}$ & 0.543 & 0.05072 \\
\hline $\mathrm{V}_{\text {pits }}$ & -0.630 & -0.01427 \\
\hline $\mathrm{V}_{\text {bonds }}$ & 0.358 & 0.33640 \\
\hline
\end{tabular}

\section{Conclusions}

Based on the results obtained, the following conclusions can be drawn:

1. The main factor affecting the mixing time of the components of the formulation is the modulus of viscosity, with an increase in which the mixing time increases. Therefore, it is necessary to try to reduce the modulus of viscosity by introducing special components.

2. The main factor affecting the uniform distribution of the components of the formulation in the volume of the mixed mass is the difference between the specific weights of the components of the formulation and the order of their introduction during mixing. The component with a high specific weight should be introduced last.

3. The fillers in the form of fused alumina and glass microspheres have a hardening effect. The influence of glass spheres is more noticeable.

4. Introduction of fruit pits as a filler leads to the softening of the wheel body.

5. The influence of the components of the formulation of the wheel on the strength and the impact strength is about the same. The percentage of grains has the weakest effect (pair correlation coefficient for grain is 0.293 , for other components its value ranges from $0.5-0.6)$.

6. Introduction of glass and fused alumina microspheres to the abrasive mass increases the wheel strength stability.

7. Increasing the percentage of abrasive grains, bond and fruit pits leads to a decrease in the stability of physical and mechanical properties of the wheel.

\section{References}

1. H. Jamshidi, M. Gurtan, E. Budak, Mater. Proc. Techn., 273, 116239 (2019)

2. E. Brinksmeier, A. Giwerzew, Wear, 258, 62 (2005)

3. P. Krajnik, J. Kopač, Mech. Eng., 50, 206 (2004)

4. Y. Qiu, H Huang, X. Xu, Adv. Manufact. Tech., 97, 3873 (2018)

5. W. Peng, C. Yao, X. Xu, App. Mech. and Mater., 126, 38 (2012)

6. W. Tillmann, E. Vogli, J. Nebel, Therm. Spr. Techn., 16, 751 (2007)

7. S. Xu, J. Zhao, W. Zou, Diam. and Abr. Eng., 2, 69 (2007)

8. S. Kryukov, N. Baidakova, P. Bochkarev, LNME, 9783319956299, 1427 (2019)

9. Y. Falkenberg, Grind. and Abr., 27 (2002)

10. Luther, B. Norris, Modern Casting, 85:1, 35 (1995)

11. V. Starkov, E. Polkanov, Superhard Mater., 37:1, 44 (2015)

12. N.V. Baidakova, T.N. Orlova, Pro. Eng., 206, 194 (2017)

13. V. Lyukshin, D. Shatko, P. Strelnikov, L. Shutko. Advances in Engineering Research, 176, (Atlantis Press, 2018)

14. D. Shatko V. Lyukshin, V. Bakumenko, Mater. Sci. Eng., 142, (2016)

15. D. Shatko, V. Lyukshin, P. Strelnikov. Technologies and materials of modern engineering. Materials Science Forum. 927, (Trans Tech Publications, 2018) 